\title{
Rasayana (Rejuvenation) in Tradition And in Recent Studies
}

\section{Marthanda Varma Sankaran Valiathan *}

Rasayana is one of the eight branches of Ayurveda and has been in vogue for over two thousand years. It remains popular even today and drugs for rasayana are among the top selling products in Ayurvedic formulary.

While ageing is a natural process which cannot be prevented, rejuvenant therapy is based on the concept that the infirmities associated with ageing could be prevented. The key principle of rejuvenant therapy is to smoothen the pathway of nutrients to replenish body tissues which are always depleting and degrading. Rejuvenant therapy was carried out in two modes - intramural and extramural. As the intramural method called for indoor facilities and involved many restrictions, the extramural method - simpler and hassle free - has been more popular.

There have been studies of rejuvenant procedures in the past, which looked at gross effects such as "feel good factor" etc., which provided little evidence of rejuvenation at the biological level. Recently two published studies have shown that Amalaki Rasayana significantly reduces breaks of single and double strand DNA in the neurons and astrocytes of rats (Subba Rao); and confirm that it enhances the life span, fecundity, thermal tolerance, starvation tolerance and other biological markers in drosophila (Lakhotia). These studies form part of a new initiative - Ayurvedic Biology - which consists of rigorous studies in modern science based on cues from Ayurveda.

\footnotetext{
* Marthanda Varma Sankaran Valiathan, Ch.M, FRCS, FRCS (C), FRCP, D.Sc (h.c) ,

"Rasayana (rejuvenation) in tradition and in recent studies"

Prof. M.S. Valiathan, National Research Professor, Manipal University, Manipal, Karnataka
} 